\title{
FISH Karyotype of 85 Common Wheat Cultivars/Lines Displayed by ND-FISH Using Oligonucleotide Probes
}

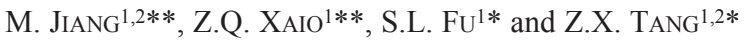 \\ ${ }^{1}$ Province Key Laboratory of Plant Breeding and Genetics, Sichuan Agricultural University, \\ Wenjiang, Chengdu 611130, China \\ ${ }^{2}$ Institute of Ecological Agriculture, Sichuan Agricultural University, Wenjiang, Chengdu 611130, China
}

(Received 20 March 2017; Accepted 04 July 2017;

Communicated by M. Molnár-Láng)

Fluorescence in situ hybridization (FISH) can reveal minor structural differences of chromosomes. The karyotype of common wheat (Triticum aestivum L.) based on FISH pattern is seldom reported. In this study, non-denaturing FISH (ND-FISH) using Oligo-pSc119.2-1, Oligo-pTa535-1 and (AAG) 6 as probes was used to investigate the chromosomal structure of 85 common wheat including 83 wheat-rye 1 RS.1BL translocation cultivars/lines, a wheatrye 1RS.1AL translocation cultivar Amigo and Chinese Spring (CS). Two, three, two, three, six, three and four structural types respectively for $1 \mathrm{~A}, 2 \mathrm{~A}, 3 \mathrm{~A}, 4 \mathrm{~A}, 5 \mathrm{~A}, 6 \mathrm{~A}$ and $7 \mathrm{~A}$ chromosomes were observed. Two, eight, two, two, four and six types of chromosome for $2 \mathrm{~B}, 3 \mathrm{~B}$, $4 \mathrm{~B}, 5 \mathrm{~B}, 6 \mathrm{~B}$ and $7 \mathrm{~B}$ were respectively detected. The structure of $1 \mathrm{~B}$ chromosomes in Amigo and $\mathrm{CS}$ is different. Five, two, two and two types of chromosomal structure respectively for 1D, 2D, 3D and 5D were distinguished. Polymorphisms of 1RS.1BL, 4D, 6D and 7D chromosomes were not detected. Chromosomes $1 \mathrm{~A}^{\mathrm{I}}, 2 \mathrm{~A}^{\mathrm{I}}, 3 \mathrm{~A}^{\mathrm{I}}, 4 \mathrm{~A}^{\mathrm{I}}, 5 \mathrm{~A}^{\mathrm{III}}, 6 \mathrm{~A}^{\mathrm{I}}, 7 \mathrm{~A}^{\mathrm{III}}, 2 \mathrm{~B}^{\mathrm{I}}, 3 \mathrm{~B}^{\mathrm{V}}$, $4 \mathrm{~B}^{\mathrm{I}}, 5 \mathrm{~B}^{\mathrm{II}}, 6 \mathrm{~B}^{\mathrm{III}}, 7 \mathrm{~B}^{\mathrm{I}}, 1 \mathrm{D}^{\mathrm{IV}}, 2 \mathrm{D}^{\mathrm{I}}, 3 \mathrm{D}^{\mathrm{I}}$ and $5 \mathrm{D}^{\mathrm{II}}$ appeared in these 85 wheat cultivars/lines at high frequency. Each of the 85 wheat cultivars/lines has a unique karyotype. Amigo is a complex translocation cultivar. The FISH karyotype of wheat chromosomes built in this study provide a reference for the future analyzing wheat genetic stocks and help to learn structural variations of wheat chromosomes. In addition, the results in this study indicate that oligonucleotide probes and ND-FISH technology can be used to identify individual wheat cultivar.

Keywords: Wheat; 1RS.1BL translocation; chromosome; polymorphism; ND-FISH

\section{Introduction}

To investigate genetic polymorphisms of common wheat (Triticum aestivum L.) is important for wheat cultivar improvement. Molecular markers are often used to investigate genetic polymorphisms of wheat and they provide useful assistance to increase selection efficiency in crop breeding program (Landieva et al. 2007). In fact, the cytogenetic methods are also valuable for displaying genome architecture and essential chromosomal land-

\footnotetext{
*Corresponding authors; E-mails: fushulan@sicau.edu.cn; zxtang@sicau.edu.cn

**These authors contributed equally to this work.
} 
marks of wheat (Sharma et al. 2016). When the standard wheat karyotype based on C-band was developed (Gill et al. 1991), C-banding technology was often used to identify wheat chromosomes and to investigate the polymorphism of wheat chromosomes (Friebe and Gill 1994; Badaeva et al. 2007). In addition, C-banding can be used to detect some chromosomal rearrangements such as translocations and inversions. However, the technology of C-banding is difficult and minor alterations of wheat chromosomes may not be detected by this classical cytogenetics method (Badaeva et al. 2007). Fluorescence in situ hybridization (FISH) is a useful and convenient method for identification of wheat chromosomes. The FISH karyotype of common wheat variety Chinese Spring was developed using tandem repeats as probes (Mukai et al. 1993; Pedersen and Langridge 1997) and it provides a standard for researchers to identify chromosomes of common wheat. Polymorphisms of wheat cultivars were investigated by FISH analysis and some kinds of structural variations of wheat chromosomes were observed (Schneider et al. 2003; Carvalho et al. 2013). FISH technology has also been widely used to analyze the chromosomes of hybrids between wheat and its wild relatives (Mirzaghaderi et al. 2014; Tang et al. 2014a; Delgado et al. 2017) and some new types of chromosomes were detected (Tang et al. 2014a). To build FISH karyotype of wheat chromosomes is useful for understanding genomic architecture and organization of wheat. However, common wheat karyotype based on FISH analysis is still limited.

With the developing of FISH technology, non-denaturing fluorescence in-situ hybridization (ND-FISH) technique, which uses oligonucleotides as probes, occurred and it can be conveniently used to analyze plant chromosomes (Cuadrado et al. 2009; Cuadrado et al. 2010; Pavia et al. 2014; Kirov et al. 2017; Zhu et al. 2017). Compared with traditional FISH technique, ND-FISH uses synthetic oligo-probes to replace the preparation and labeling of long probe sequences, and the denaturing of probes and chromosomes are not needed. So, the convenient feature of ND-FISH is that oligo-probes labeled with fluorochrome can be purchased directly from commercial sources, both chromosomes and synthetic oligo-probes are not needed to be denatured before hybridization, and the hybridization time can be reduced to one hour (Cuadrado et al. 2009; Cuadrado et al. 2010; Fu et al. 2015). To get suitable oligonucleotide probes is important for a successful ND-FISH analysis. Oligo-probes Oligo-pSc119.2 and Oligo-pTa535 have been developed for the ND-FISH of wheat chromosomes (Tang et al. 2014b; Fu et al. 2015). The combination of this two kinds of oligo-probes can replace the roles of repetitive DNA sequences pSc119.2 and pTa-535 to successfully identify the 21 chromosomes of common wheat (Tang et al. 2014b). Especially, probe Oligo-pTa535, which was derived from the repetitive DNA sequence pTa-535 (Komuro et al. 2013), is able to identify A- and D-genome chromosomes well (Tang et al. 2014b; Badaeva et al. 2015). Now, ND-FISH technique is often used to analyze the chromosomes of wheat and its relatives because it is convenient (Carmona et al. 2013; Carvalho et al. 2013; Cabo et al. 2014; Fu et al. 2015; Badaeva et al. 2015; Delgado et al 2017; Li et al. 2016; Tang et al. 2016; Du et al. 2017; Xiao et al. 2017). Therefore, ND-FISH technology can be used for the large-scale analysis of wheat chromosomes and to rich the FISH karyotype of wheat chromosomes. 
In the present study, ND-FISH analysis using Oligo-pSc119.2-1, Oligo-pTa535-1 and $(\mathrm{AAG})_{6}$ as probes was used to investigate the chromosomal structure of 83 wheat-rye 1RS.1BL translocation cultivars/lines, a wheat-rye 1RS.1AL translocation cultivar Amigo and a common wheat Chinese Spring (CS) because 1RS.1BL and 1RS.1AL translocation chromosomes have played an important role in wheat breeding program. The FISH karyotype of wheat chromosomes built in this study provide a reference for the future analyzing wheat genetic stocks.

\section{Materials and Methods}

\section{Plant materials}

A total of 85 materials including 83 wheat-rye 1RS.1BL translocation cultivars/lines, one wheat-rye 1RS.1AL translocation cultivar Amigo and one common wheat Chinese Spring were used in this study. The materials were listed in Table 1. Amigo and Aurora were from the American Germplasm Resources Information Network (GRIN). Cultivars Yimai 8, Chuanmai 35 and Chuanmai 55 were kindly provided by Dr. Ennian Yang, Crop Research Institute, Sichuan Academy of Agricultural Sciences, Sichuan, China. Cultivars Chuannong 11, Chuannong 12, Chuannong 17 and Chuannong 18 were provided by our laboratory. Chinese Spring was kept in our laboratory. The rest materials used in this study were kindly provided by Professor Fangpu Han, Institute of Genetics and Developmental Biology, Chinese Academy of Science, Beijing, China.

\section{ND-FISH analysis}

The root-tip preparations of the 85 materials were prepared through the methods described by Han et al. (2006). Oligonucleotide probes Oligo-pSc119.2-1, Oligo-pTa535-1 (Tang et al. 2014b) and (AAG) 6 were used for ND-FISH analysis. Probes OligopSc119.2-1, Oligo-pTa535-1 and (AAG) ${ }_{6}$ were 5'end-labelled with 6-carboxyfluorescein (6-FAM), 6-carboxytetramethylrhodamine (Tamra) and Cy5, respectively. Oligonucleotide probes were synthesized by Shanghai Invitrogen Biotechnology Co. Ltd. (Shanghai, China). The synthesized oligonucleotide probes were diluted by using $1 \times \mathrm{TE}$ solution $(\mathrm{pH}$ 7.0). Probe amounts per slide were operated according to the methods described by Fu et al. (2015). The probe mixture containing each probe, $2 \times \mathrm{SSC}$ and $1 \times \mathrm{TE}$ buffer $(\mathrm{pH} 7.0$, total volume $=10 \mu \mathrm{l}$ ) was dropped at the center of the cell spreads, and covered with glass coverslip. Slides were immediately stored in a moist box at $42^{\circ} \mathrm{C}$ for $1 \mathrm{~h}$ and washed 15 seconds in $2 \times \mathrm{SSC}$ with the temperature $42^{\circ} \mathrm{C}$. An epifluorescence microscope (BX51, Olympus) equipped with a cooled charge-coupled device camera operated with HCIMAGE Live software (version 2.0.1.5) was used to take images. For each of the 85 wheat cultivars/lines, five seeds were used and at least 7-10 metaphase cells on each slide were detected. 


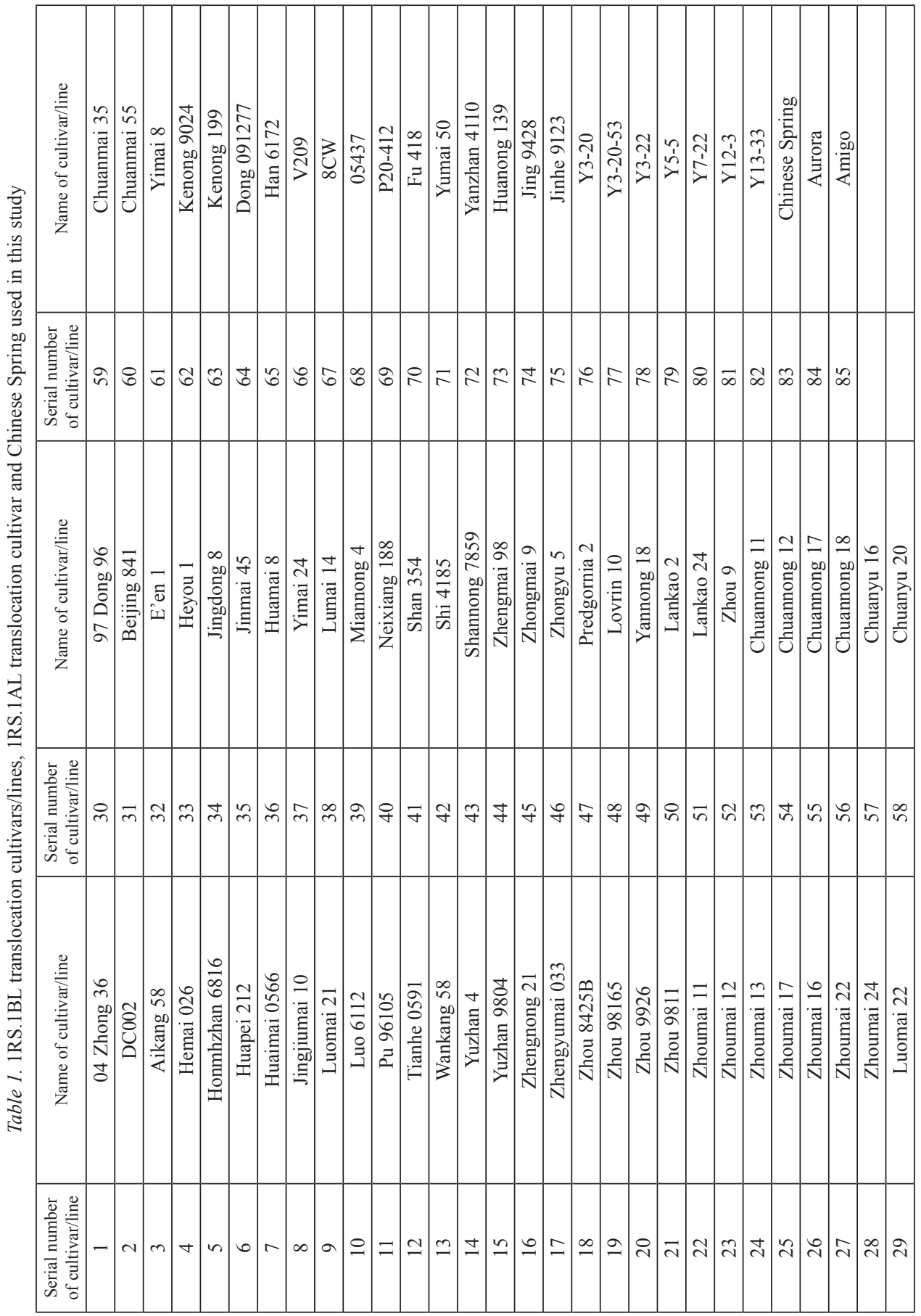




\section{Results}

Polymorphisms of A-genome chromosomes

Among the 85 wheat cultivars/lines, two, three, two, three, six, three and four structural types respectively for 1A, 2A, 3A, 4A, 5A, 6A and 7A chromosomes were observed (Figs 1, S1*, S2, S3, S4, S5, S6). Oligo-pTa535-1 produced strong signal on telomeric region of the short arm of type $1 \mathrm{~A}^{\mathrm{I}}$ chromosome and this signal disappeared from this region of type $1 \mathrm{~A}^{\mathrm{II}}$ chromosome (Figs $1, \mathrm{~S} 1, \mathrm{~S} 2, \mathrm{~S} 5, \mathrm{~S} 6, \mathrm{~S} 7$ ). $2 \mathrm{~A}^{\mathrm{I}}$ and $2 \mathrm{~A}^{\mathrm{II}}$ chromosomes contained two clear signal bands of probe Oligo-pTa535-1 on short arms, and only one clear band of this probe on short arm of $2 \mathrm{~A}^{\mathrm{III}}$ chromosome can be observed (Figs 1, S1, S2). Probe Oligo-pSc119.2-1 produced a clear signal on the telomeric region of the long arm of $2 \mathrm{~A}^{\mathrm{II}}$ chromosome (Figs 1, S1, S2). Probe Oligo-pTa535-1 produced misty signals on the telomeric and sub-telomeric regions of the long arm of $3 \mathrm{~A}^{\mathrm{I}}$ chromosome but a clear signal band on the sub-telomeric region of the long arm of $3 \mathrm{~A}^{\mathrm{II}}$ chromosome (Figs 1, S2). Signal of $(\mathrm{AAG})_{6}$ can be observed on the telomeric region of the long arm of $4 \mathrm{~A}^{\mathrm{I}}$ chromosome, and it disappeared from $4 \mathrm{~A}^{\mathrm{II}}$ and $4 \mathrm{~A}^{\mathrm{III}}$ chromosomes (Figs 1, S2, S3). The signal of OligopSc119.2-1 cannot be observed on $4 \mathrm{~A}^{\mathrm{III}}$ chromosomes (Figs 1, S3). Probes OligopSc119.2-1 and Oligo-pTa535-1 produced different patterns on $5 \mathrm{~A}^{\mathrm{I}}, 5 \mathrm{~A}^{\mathrm{II}}, 5 \mathrm{~A}^{\mathrm{III}}, 5 \mathrm{~A}^{\mathrm{IV}}$ and $5 \mathrm{~A}^{\mathrm{V}}$ chromosomes, and no signals of Oligo-pSc119.2-1 and Oligo-pTa535-1 were observed on $5 \mathrm{~A}^{\mathrm{VI}}$ chromosome (Figs 1, S1, S2, S3). Both the different types of 6A and 7A



Figure 1. The cut-and-paste chromosomes representing different types of A-genome chromosomes, 1RS.1AL translocation chromosomes. $6 \mathrm{~A} / 6 \mathrm{~B}$ and $7 \mathrm{~A} / 7 \mathrm{~B}$ translocation chromosomes. Chromosomes at left side were hybridized with probes Oligo-pSc119.2-1 (green) and Oligo-pTa-535-1 (red). Chromosomes at right side were hybridized with probe $(\mathrm{AAG})_{6}$ (red)

*Further details about the Electronic Supplementary Material (ESM) can be found at the end of the article. 
chromosomes were displayed by probe $(\mathrm{AAG})_{6}$ (Fig. 1). The long arms of $6 \mathrm{~A}^{\mathrm{I}}$ and $6 \mathrm{~A}^{\mathrm{III}}$ chromosomes contained two and one signal bands of $(\mathrm{AAG})_{6}$, respectively, and chromosome $6 \mathrm{~A}^{\mathrm{II}}$ had no this signal (Figs 1, S1, S2, S3). The telomeric regions of the short and long arms of $7 \mathrm{~A}^{\mathrm{I}}$ and $7 \mathrm{~A}^{\mathrm{II}}$ chromosomes carried (AAG) $)_{6}$ signal, and this signal also appeared at the sub-telomeric region of the long arm of $7 \mathrm{~A}^{\mathrm{II}}$ chromosome (Figs 1, S5, S7). Signal of $(\mathrm{AAG})_{6}$ disappeared from the short arm of $7 \mathrm{~A}^{\mathrm{III}}$ chromosome, and $7 \mathrm{~A}^{\mathrm{IV}}$ chromosome did not contain this signal (Figs 1, S1, S2, S3, S4, S5, S6, S7).

\section{Polymorphisms of B-genome chromosomes}

Among the 85 materials used in this study, 83 contain a pair of 1RS.1BL translocation chromosomes, and probes Oligo-pSc119.2-1, Oligo-pTa535-1 and (AAG) 6 didn't exhibit the polymorphism of these translocation chromosomes (Figs 2, S1, S2, S3, S4, S5, S6, S7). The 1B chromosomes in CS and Amigo were different. The telomeric regions of the short arms of 1B chromosomes of Amigo contain strong Oligo-pTa535-1 signal, but the 1B chromosomes of CS almost have no these signals (Figs 2, S7). Additionally, the probe $(\mathrm{AAG})_{6}$ also displays different signal patterns between the two kinds of $1 \mathrm{~B}$ chromosomes (Figs 2, S7). Two types of 2B chromosomes were observed (Fig. 2). The signal patterns of Oligo-pSc119.2-1 on chromosomes $2 \mathrm{~B}^{\mathrm{I}}$ and $2 \mathrm{~B}^{\mathrm{II}}$ were different. The telomeric region

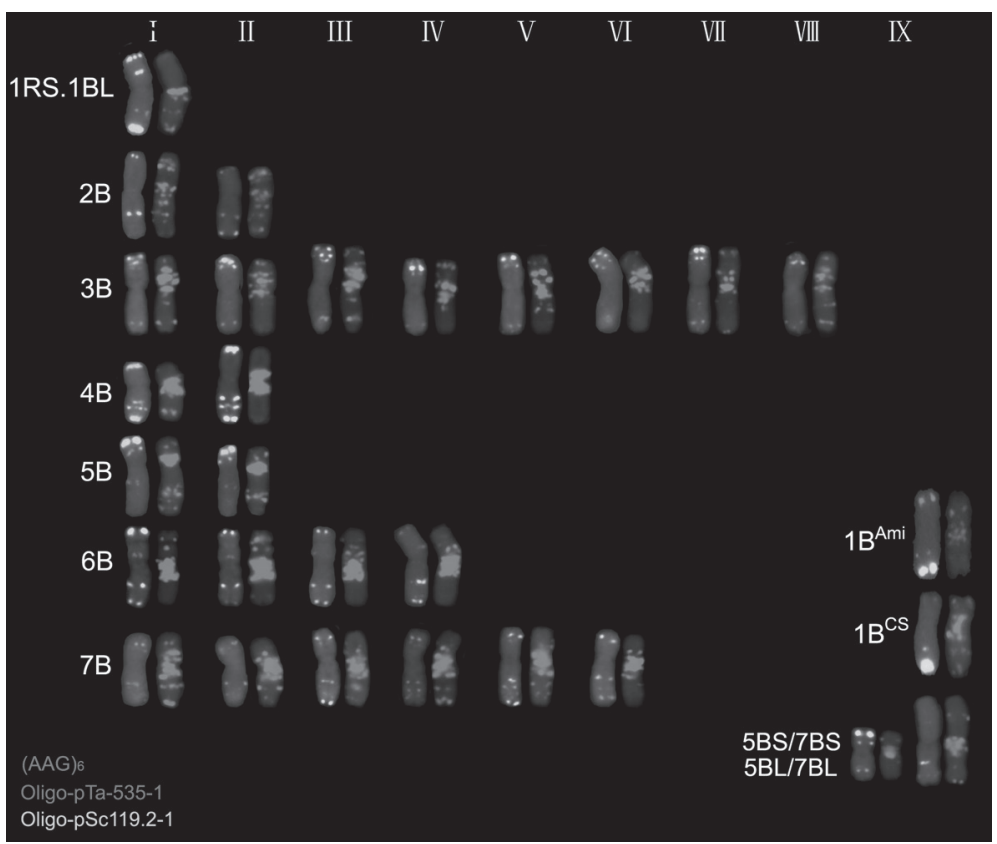

Figure 2. The cut-and-paste chromosomes representing different types of B-genome chromosomes and 5B/7B translocation chromosomes. Chromosomes at left side were hybridized with probes Oligo-pSc119.2-1 (green) and Oligo-pTa-535-1 (red). Chromosomes at right side were hybridized with probe (AAG) 6 (red). 1B ${ }^{\text {Ami indi- }}$ cates the $1 \mathrm{~B}$ chromosomes of Amigo. $1 \mathrm{~B}^{\mathrm{CS}}$ indicates $1 \mathrm{~B}$ chromosomes of Chinese Spring 
of the long arm of $2 \mathrm{~B}^{\mathrm{II}}$ chromosome possessed clear signal of Oligo-pSc119.2-1, and this signal was not observed on this region of $2 \mathrm{~B}^{\mathrm{I}}$ chromosome (Figs 2, S3). Eight types of $3 \mathrm{~B}$ chromosomes were displayed by probes (AAG) 6 and Oligo-pSc119.2-1 (Figs 2, S1, S2, S3, S4). Probe Oligo-pSc119.2-1 produced three signal bands on the short arms of 3B ${ }^{\text {III }}$ and $3 \mathrm{~B}^{\mathrm{VI}}$ chromosomes, and produced two signal bands on the short arms of other six types of 3B chromosomes, and the signal strength was different among them (Figs 2, S1, $\mathrm{S} 2, \mathrm{~S} 3, \mathrm{~S} 4, \mathrm{~S} 5, \mathrm{~S} 6, \mathrm{~S} 7)$. The signal patterns of $(\mathrm{AAG})_{6}$ on the $3 \mathrm{~B}^{\mathrm{I}}$ and $3 \mathrm{~B}^{\mathrm{III}}$ are same, and the similar signal patterns of (AAG) ${ }_{6}$ can be observed on $3 \mathrm{~B}^{\mathrm{II}}$ and $3 \mathrm{~B}^{\mathrm{VI}}$ (Figs $2, \mathrm{~S} 1, \mathrm{~S} 2$, S3, S4, S5, S6, S7). The differences between the two types of both 4B and 5B chromosomes were displayed by probe $(\mathrm{AAG})_{6}$. Probe $(\mathrm{AAG})_{6}$ generated one more signal band on the long arms of $4 \mathrm{~B}^{\mathrm{I}}$ and $5 \mathrm{~B}^{\mathrm{I}}$ chromosomes than that of $4 \mathrm{~B}^{\mathrm{II}}$ and $5 \mathrm{~B}^{\mathrm{II}}$ chromosomes (Figs 2, S1, S3). The four types of 6B chromosomes were differentiated by the strength, the absence or the presence of Oligo-pSc119.2-1 signals (Figs 2, S1, S2, S5). Probe Oligo-pSc119.2-1 produced one signal band on both the short and long arms of $7 \mathrm{~B}^{\mathrm{I}}$ and $7 \mathrm{~B}^{\mathrm{II}}$ chromosomes (Figs 2, S1, S4). Probe Oligo-pSc119.2-1 produced more than one clear signal bands on the long arms of $7 \mathrm{~B}^{\mathrm{III}}, 7 \mathrm{~B}^{\mathrm{IV}}, 7 \mathrm{~B}^{\mathrm{V}}$ and $7 \mathrm{~B}^{\mathrm{VI}}$ chromosomes, and the signal sites were different (Figs 2, S1, S5). The telomeric regions of the long arms of $7 \mathrm{~B}^{\mathrm{I}}$ and $7 \mathrm{~B}^{\mathrm{IV}}$ chromosomes contained (AAG) $)_{6}$ signal and this signal disappeared from this region of other types of 7B chromosomes (Figs 2, S1, S4, S5, S6). In addition, cultivar CM62 contains 5BS/7BS and 5BL/7BL translocation chromosomes (Figs 2, S5). Cultivar Amigo contains 1RS.1AL, 6AS.6AL-6BL, 6BS.6BL-6AL, 7AS/7BS and 7AL/7BL translocation chromosomes (Figs 1, S7).

\section{Polymorphisms of D-genome chromosomes}

The variation of D-genome chromosomes is lesser than that of A- and B-genome chromosomes (Figs 3, S1, S2, S3, S4, S5, S6, S7). Five types of 1D chromosome were detected among the 85 wheat cultivars/lines (Figs 3, S1, S3, S6, S7). The short arm of 1D ${ }^{\mathrm{I}}$ chromosome contained strong signal of Oligo-pSc119.2-1, the long arms of $1 \mathrm{D}^{\mathrm{II}}$ and $1 \mathrm{D}^{\mathrm{III}}$ chromosomes contained clear signal of Oligo-pSc119.2-1, and chromosomes $1 \mathrm{D}^{\mathrm{IV}}$ $1 \mathrm{D}^{\mathrm{V}}$ did not contain this signal (Figs $3, \mathrm{~S} 1, \mathrm{~S} 6$ ). In addition, $1 \mathrm{D}^{\mathrm{III}}$ and $1 \mathrm{D}^{\mathrm{V}}$ chromosomes had no signal of $(\mathrm{AAG})_{6}$ and the short arms of $1 \mathrm{D}^{\mathrm{I}}, 1 \mathrm{D}^{\mathrm{II}}$ and $1 \mathrm{D}^{\mathrm{IV}}$ chromosomes carried

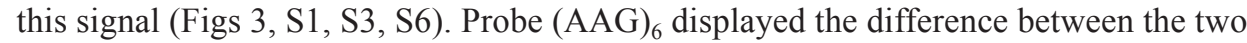
types of $2 \mathrm{D}$ chromosomes. The sub-telomeric region of the long arm of $2 \mathrm{D}^{\mathrm{II}}$ chromosome carried the signal of $(\mathrm{AAG})_{6}$ and it disappeared from the same site of $2 \mathrm{D}^{\mathrm{I}}$ chromosome (Figs 3, S2, S3, S5, S6). The two types of 3D chromosomes can be distinguished by the signal strength of Oligo-pSc119.2-1. The signal of Oligo-pSc119.2-1 on 3D ${ }^{\mathrm{I}}$ chromosome was very weak, and on 3D ${ }^{I I}$ chromosome was strong (Figs 3, S2, S5, S6). Probe Oligo-pTa535-1 produced strong signal band on the sub-telomeric region of the long arm of $5 \mathrm{D}^{\mathrm{II}}$ chromosome and generated blurry signal on the same region of $5 \mathrm{D}^{\mathrm{I}}$ chromosome (Figs 3, S1, S2, S3, S4, S5, S6). 4D, 6D and 7D chromosomes have only one type of structure among the 85 wheat cultivars/lines (Figs 3, S1, S2, S3, S4, S5, S6, S7). 




Figure 3. The cut-and-paste chromosomes representing different types of D-genome chromosomes. Chromosomes at left side were hybridized with probes Oligo-pSc119.2-1 (green) and Oligo-pTa-535-1 (red). Chromosomes at right side were hybridized with probe (AAG) 6 (red)

\section{Distributions of different types of wheat chromosomes among the 85 wheat cultivars/lines}

The distributions of different types of A-, B- and D- genome chromosomes were listed in Table 2. From Table 2, it can be noted that chromosomes $1 \mathrm{~A}^{\mathrm{I}}, 2 \mathrm{~A}^{\mathrm{I}}, 3 \mathrm{~A}^{\mathrm{I}}, 4 \mathrm{~A}^{\mathrm{I}}, 5 \mathrm{~A}^{\mathrm{I}}, 6 \mathrm{~A}^{\mathrm{I}}$, $7 \mathrm{~A}^{\mathrm{III}}, 2 \mathrm{~B}^{\mathrm{I}}, 3 \mathrm{~B}^{\mathrm{V}}, 4 \mathrm{~B}^{\mathrm{I}}, 5 \mathrm{~B}^{\mathrm{II}}, 6 \mathrm{~B}^{\mathrm{III}}, 7 \mathrm{~B}^{\mathrm{I}}, 1 \mathrm{D}^{\mathrm{IV}}, 2 \mathrm{D}^{\mathrm{I}}, 3 \mathrm{D}^{\mathrm{I}}$ and $5 \mathrm{D}^{\mathrm{II}}$ appeared in these 85 wheat cultivars/lines at high frequency. In the present study, chromosomes $2 \mathrm{~A}^{\mathrm{II}}, 2 \mathrm{~A}^{\mathrm{III}}, 4 \mathrm{~A}^{\mathrm{II}}$, $4 \mathrm{~A}^{\mathrm{III}}, 5 \mathrm{~A}^{\mathrm{V}}, 5 \mathrm{~A}^{\mathrm{VI}}, 6 \mathrm{~A}^{\mathrm{III}}, 7 \mathrm{~A}^{\mathrm{I}}, 7 \mathrm{~A}^{\mathrm{IV}}, 2 \mathrm{~B}^{\mathrm{II}}, 3 \mathrm{~B}^{\mathrm{I}}, 3 \mathrm{~B}^{\mathrm{II}}, 3 \mathrm{~B}^{\mathrm{III}}, 3 \mathrm{~B}^{\mathrm{VIII}}, 6 \mathrm{~B}^{\mathrm{II}}, 7 \mathrm{~B}^{\mathrm{III}}, 7 \mathrm{~B}^{\mathrm{IV}}, 7 \mathrm{~B}^{\mathrm{V}}, 7 \mathrm{~B}^{\mathrm{VI}}$, 5BS/7BS, 5BL/7BL, 6AS.6AL-6BL, 6BS.6BL-6AL, 7AS/7BS, 7AL/7BL, $1 \mathrm{D}^{\mathrm{II}}$, $1 \mathrm{D}^{\mathrm{III}}$ and $1 \mathrm{D}^{\mathrm{V}}$ were present in less than ten cultivars/lines (Table 2). Chromosomes $5 \mathrm{~A}^{\mathrm{V}}, 5 \mathrm{~A}^{\mathrm{VI}}$, $7 \mathrm{~B}^{\mathrm{V}}, 7 \mathrm{~B}^{\mathrm{VI}}$, 5BS/7BS, 5BL/7BL, 6AS.6AL-6BL, 6BS.6BL-6AL, 7AS/7BS, 7AL/7BL and $1 \mathrm{D}^{\mathrm{III}}$ only occurred in one cultivar/line (Table 2). These chromosomes are rare. However, the three kinds of probes used in this study could not reflect the polymorphism of 1RS.1BL, 4D, 6D, and 7D chromosomes. In addition, each of the common wheat used in this study has a unique karyotype (Table S1). That is, each of the 85 cultivars/lines has a different chromosomal composition. 


\begin{tabular}{|c|c|c|c|c|c|c|c|c|c|c|c|c|c|}
\hline 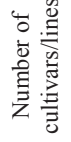 & 은 & $\sim$ & $m$ & $\cong$ & 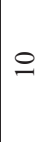 & $\stackrel{\sim}{\sim}$ & $i_{n}^{\infty}$ & - & $=$ & $\nabla$ & Ұ & 2 & - \\
\hline 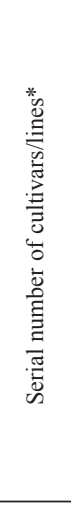 & 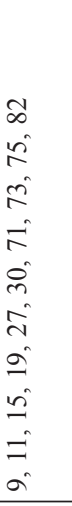 & $\begin{array}{l}\infty \\
\infty \\
i \\
\end{array}$ & $\begin{array}{l}b \\
\text { in } \\
\text { ñ }\end{array}$ & 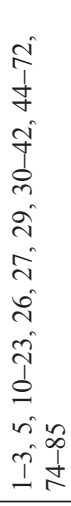 & 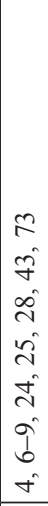 & 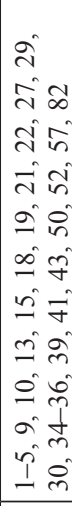 & 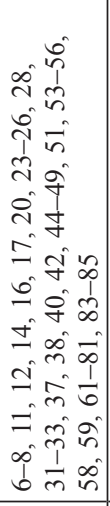 & 8 & 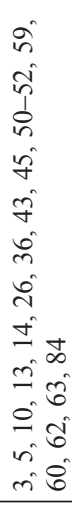 &  &  & 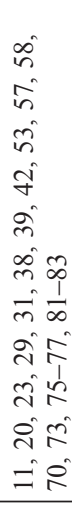 & $\infty$ \\
\hline 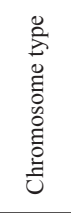 & m & $\begin{array}{l}\sum_{m} \\
\text { m }\end{array}$ & $\begin{array}{l}\bar{J} \\
\text { m }\end{array}$ & $\vec{q}$ & 产 & $\ddot{n}$ & 商 & 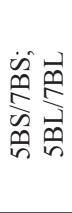 & $\overline{\widetilde{\sigma}}$ & ขै & 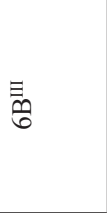 & ڤै & 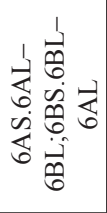 \\
\hline 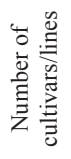 & $\widetilde{\sigma}$ & $\tilde{\approx}$ & - & $\therefore$ & in & $m$ & $\nabla$ & $\Xi$ & $\triangleright$ & $\sim$ & $m$ & $=$ & 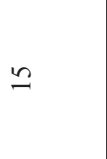 \\
\hline 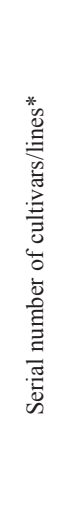 & 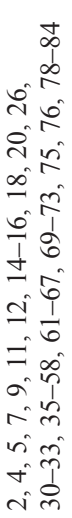 & 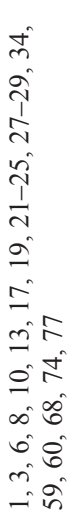 & $\infty$ &  & \begin{tabular}{l}
2 \\
\multirow{0}{0}{} \\
$\dot{0}$ \\
$\dot{n}$ \\
$\dot{m}$ \\
$\dot{ \pm}$
\end{tabular} & $\begin{array}{l}m \\
\hat{n} \\
\dot{q} \\
\dot{q}\end{array}$ & 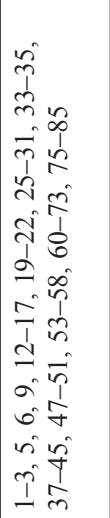 & 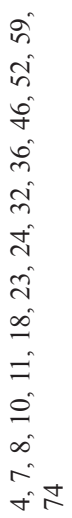 & 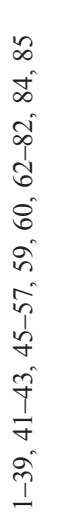 & $\begin{array}{l}\infty \\
\dot{f}\end{array}$ & $\begin{array}{l}\overrightarrow{0} \\
\infty \\
n \\
\dot{q}\end{array}$ & 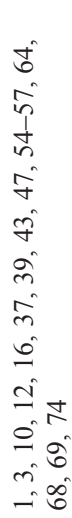 & 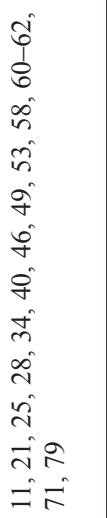 \\
\hline 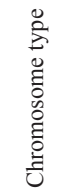 & 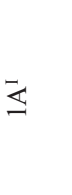 & $\underset{\Xi}{\Xi}$ & $\begin{array}{l}\text { ¿ } \\
\ddot{\mathscr{n}} \\
\stackrel{\Xi}{2}\end{array}$ & 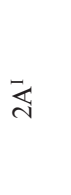 & $\underset{\sim}{\mathbb{N}}$ & 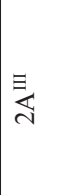 & 离 & 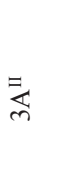 & ঔ & 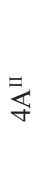 & $\underset{子}{\rightleftarrows}$ & 离 & $\underset{n}{E}$ \\
\hline
\end{tabular}




\begin{tabular}{|c|c|c|c|c|c|c|c|c|c|c|c|c|c|}
\hline 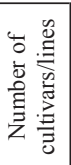 & 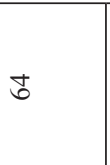 & $a$ & 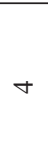 & $\nabla$ & - & - & - & - & $\because$ & $\stackrel{\varrho}{ }$ & - & $n$ & $\nabla$ \\
\hline 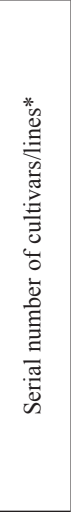 & 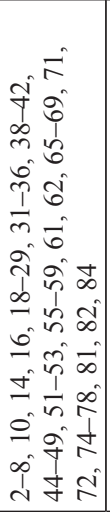 & 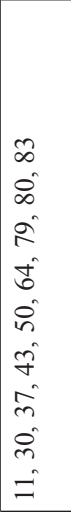 & 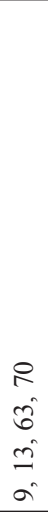 & $\begin{array}{l}n \\
\stackrel{n}{n} \\
\stackrel{0}{a} \\
\stackrel{a}{a}\end{array}$ & - & 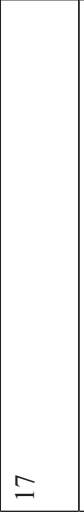 & 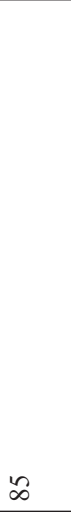 & 8 & 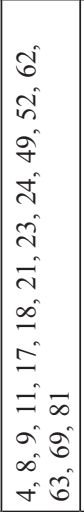 & 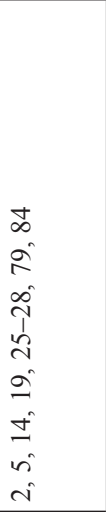 & $\nabla$ & 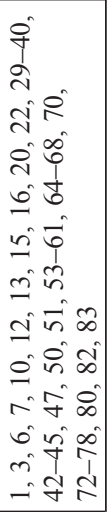 & $\begin{array}{l}\infty \\
\infty \\
\infty \\
+ \\
0 \\
\dot{f} \\
\dot{f}\end{array}$ \\
\hline  & $\overline{\underline{x}}$ & 商 & 总 & $\stackrel{z}{q}$ & 家 & $\stackrel{5}{\stackrel{m}{*}}$ & 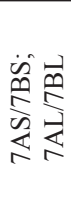 & 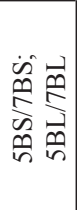 & $\bar{\theta}$ & قิ & 㗐 & 引 & $\overrightarrow{\mathrm{\theta}}$ \\
\hline  & $\ddot{n}$ & 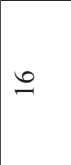 & - & - & $\hat{6}$ & $\because$ & 0 & - & $\infty$ & ల్ల & $\stackrel{\leftrightarrow}{\sim}$ & $m$ & - \\
\hline 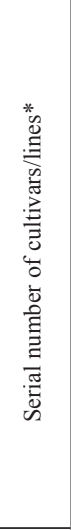 & 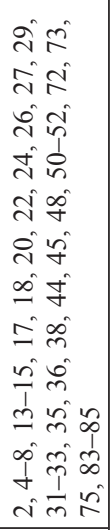 & 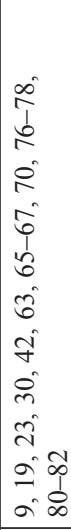 & in & $F$ & 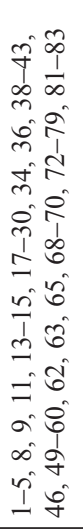 & 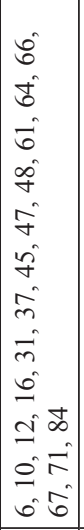 & 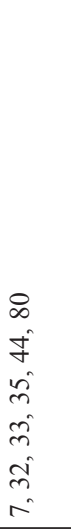 & $\infty$ & 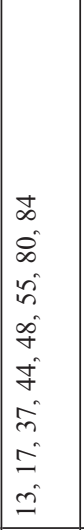 & 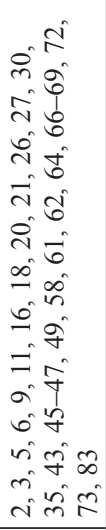 &  & $\begin{array}{l}8 \\
8 \\
i n \\
0 \\
n\end{array}$ & 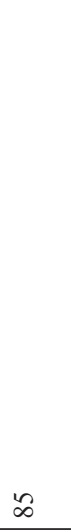 \\
\hline 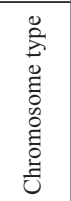 & $\underset{n}{\Xi}$ & $\sum_{n}$ & 离 & 胥 & ¿্ర & 必 & 疋 & 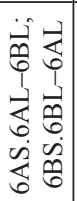 & 廷 & $\underset{\Sigma}{E}$ & $\underset{\Omega}{\mathbb{S}}$ & $\underset{\Sigma}{\sharp}$ & 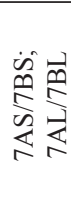 \\
\hline
\end{tabular}




\begin{tabular}{|c|c|c|c|c|c|c|c|c|c|c|}
\hline 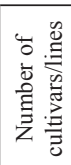 & $\stackrel{\infty}{n}$ & $\widehat{\imath}$ & $\mathbb{N}$ & 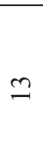 & $\ddot{\infty}$ & 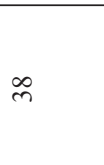 & $\tilde{f}$ & $\infty$ & $\mathscr{\infty}$ & \\
\hline 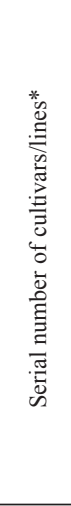 & 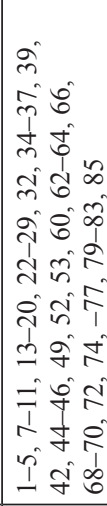 & 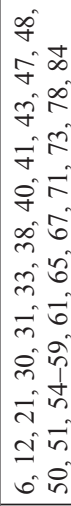 & 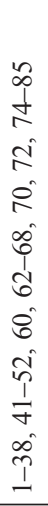 &  & $\begin{array}{l}n \\
\infty \\
1\end{array}$ & 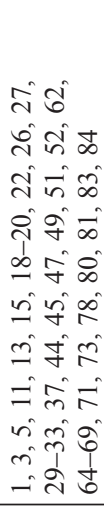 & 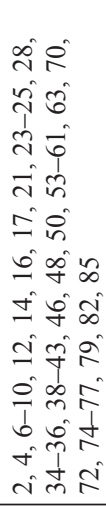 & $\begin{array}{l}n \\
\infty \\
1\end{array}$ & $\begin{array}{l}n \\
1 \\
1\end{array}$ & \\
\hline 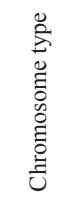 & নิ & ลิ & ले & लि & ค & $\bar{n}$ & 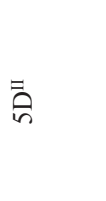 & ใ & 2 & \\
\hline 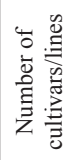 & $\infty$ & - & - & 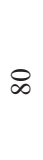 & in & $r$ & 6 & 6 & $\approx$ & 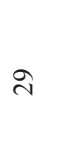 \\
\hline 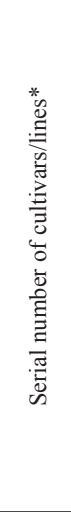 & $\begin{array}{l} \pm \\
\infty \\
1 \\
\infty \\
-1\end{array}$ & $\tilde{\infty}$ & $\cong$ & 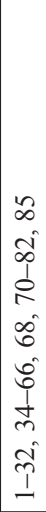 & $\begin{array}{l}+ \\
\infty \\
\infty \\
\hat{0} \\
\hat{0} \\
\hat{0} \\
\hat{n}\end{array}$ & 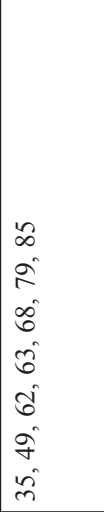 & $\begin{array}{l}3 \\
\infty \\
\delta \\
\delta \\
f \\
\tilde{f} \\
\dot{f} \\
m \\
m \\
\dot{d}\end{array}$ & 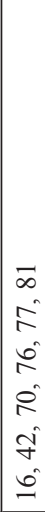 & 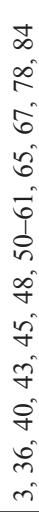 & 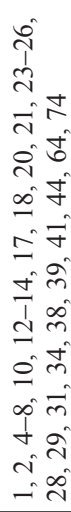 \\
\hline 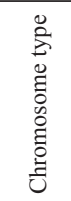 & $\begin{array}{l}\overrightarrow{0} \\
\ddot{n} \\
\underline{\underline{n}}\end{array}$ & $\begin{array}{l}0 \\
\stackrel{m}{0}\end{array}$ & 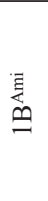 & $\vec{\sim}$ & $\stackrel{\bar{v}}{\sim}$ & $\bar{m}$ & 商 & लm & $\bar{m}$ & m \\
\hline
\end{tabular}




\section{Discussion}

Although the polymorphisms of wheat chromosomes were often displayed by C-banding technology, FISH analysis can detect subtle structural alterations of wheat chromosomes (Schneider et al. 2003; Tang et al. 2014a). Twenty-two wheat cultivars were analyzed by FISH technology using tandem repeats pSc119.2 and pAs1 as probes, and the delicate structural differences of chromosomes 4A, 5A, 1B, 2B, 3B, 5B, 6B, 7B, 1D, 2D, 3D and $4 \mathrm{D}$ were observed (Schneider et al. 2003). FISH analysis using (AAC) $)_{5}$ as probe was used to investigate 10 Old Portuguese wheat cultivars and the hybridization patterns on $1 \mathrm{~B}$ and 6B chromosomes were different among five bread wheat cultivars (Carvalho et al. 2013). Eight wheat cultivars were analyzed by ND-FISH using oligonucleotide probes, which were derived from pSc119.2 and Afa-family repetitive sequences, and the high frequency of variations of 5A, 7A, 7B and 2D chromosomes were observed (Du et al. 2017). However, the FISH karyotypes of bread wheat cultivars were still limited and this is not helpful for the future analyzing wheat genetic stocks. In the present study, the polymorphisms of chromosomes of the 85 wheat cultivars/lines was investigated by ND-FISH analysis using Oligo-pSc119.2-1, Oligo-pTa535-1 and (AAG) ${ }_{6}$ as probes, and more variations of wheat chromosomes were displayed. FISH polymorphisms of wheat chromosomes that were explained by the variation in the amount and distribution of tandem repeats might be useful for the studying of wheat genetic variations. The FISH karyotype of wheat chromosomes described in this study provides a reference for the future studying structural variations of common wheat chromosomes. In addition, the wheat chromosomes with different structure constitute the unique karyotype of each of the wheat cultivars/ lines used in this study (Table S1), therefore, oligonucleotide probes and ND-FISH technology can be used to identify individual wheat cultivar.

Amigo, a cultivar containing wheat-rye 1RS.1AL translocation chromosomes, is well known for its $G b 2, \mathrm{Lr} 24, \mathrm{Sr} 24$ and $\mathrm{Pm} 17$ genes. C-banding and multicolor FISH techniques were used to analyze the chromosomes of Amigo and it was found that Amigo contains T1BL.1BS-3Ae\#1L translocation chromosomes (Jiang et al. 1994). It was indicated that about $50 \%$ of the 1B satellite was derived from Agropyron elongatum chromosome (Jiang et al. 1994). In this study, the probe Oligo-pTa535-1 produced strong signals on the satellites of $1 \mathrm{~B}^{\mathrm{Ami}}$ chromosomes (Figs 2, S7). The satellites of $1 \mathrm{~B}^{\mathrm{CS}}$ chromosomes have no Oligo-pTa535-1 signals (Figs 2, S7). In our previous study, no strong OligopTa535-1 signals on the satellites of 1B chromosomes of other common wheat have been observed. Therefore, probes Oligo-pTa535-1 and Oligo-pSc119.2 can be used to identify T1BL.1BS-3Ae\#1L translocation chromosomes from Amigo. In addition, the 6AS.6AL6BL, 6BS.6BL-6AL, 7AS/7BS and 7AL/7BL translocation chromosomes are also discovered in this study. These results indicate that Amigo is a complex translocation cultivar.

ND-FISH using oligonucleotides as probes is a convenient way to analyze plant chromosomes. Cuadrado et al. (2009) used ND-FISH technique to analyze plant telomeres. Subsequently, ND-FISH using simple sequence repeats (SSR) as probes was used to analyze chromosomes of wheat and its relatives (Cuadrado and Jouve 2010; Cuadrado et al. 
2013; Cabo et al. 2014; Delgado et al. 2017). Fu et al. (2015) indicated that the non-SSR oligonucleotide probes could also be used for ND-FISH analysis. The oligonucleotide probes and ND-FISH technique have provided an easier and faster method for the studying of wheat chromosomes, therefore, to analyze wheat cultivars in large scale and to discover abundant structural alteration of wheat chromosomes is possible.

In conclusion, polymorphisms of wheat chromosomes can be displayed by the variation of tandem repeats in the amount and distribution. The variation of tandem repeats can be fast and easily detected by ND-FISH technology. The FISH polymorphisms of wheat chromosomes revealed by tandem repeats may be helpful for studying of wheat genetic variations.

\section{Acknowledgement}

This project was supported by the National Natural Science Foundation of China (No. 31471498).

\section{References}

Badaeva, E.D., Dedkova, O.S., Gay, G., Pukhalskyi, V.A., Zelenin, A.V., Bernard, S., Bernard, M. 2007. Chromosomal rearrangements in wheat: their types and distribution. Genome 50:907-926.

Badaeva, E.D., Amosova, A.V., Goncharov, N.P., Macas, J., Ruban, A.S., Grechishnikova, I.V., Zoshchuk, S.A., Houben, A. 2015. A set of cytogenetic markers allows the precise identification of all A-genome chromosomes in diploid and polyploidy wheat. Cytogenet. Genome Res. 146:71-79.

Cabo, S., Carvalho, A., Martin, A., Lima-Brito, J. 2014. Structural rearrangements detected in newly-formed hexaploid tritordeum after three sequential FISH experiments with repetitive DNA sequences. J. Genet. 93: 183-188. doi:10.1007/s12041-014-0328-5.

Carmona, A., Friero, E., Bustos, A.D., Jouve, N., Cuadrado, A. 2013. Cytogenetic diversity of SSR motifs within and between Hordeum species carrying the $\mathrm{H}$ genome: $H$. vulgare L. and $H$. bulbosum L. Theor. Appl. Genet. 126:949-961.

Carvalho, A., Guedes-Pinto, H., Lima-Brito, J. 2013. Polymorphism of the simple sequence repeat (AAC)5 in the nucleolar chromosomes of old Portuguese wheat cultivars. J. Genet. 92:583-586.

Cuadrado, Á., Golczyk, H., Jouve, N. 2009. A novel, simple and rapid nondenaturing FISH (ND-FISH) technique for the detection of plant telomeres. Potential used and possible target structures detected. Chromosome Res. 17:755-762.

Cuadrado, Á., Jouve, N. 2010. Chromosomal detection of simple sequence repeats (SSRs) using nondenaturing FISH (ND-FISH). Chromosoma 119:495-503.

Cuadrado, Á., Carmona, A., Jouve, N. 2013. Chromosomal characterization of the three subgenomes in the polyploids of Hordeum murinum L.: New insight into the evolution of this complex. PLoS ONE 8:e81385.

Delgado, A., Carvalho, A., Martín, C., Martín, A., Lima-Brito, J. 2017. Genomic reshuffling in advanced lines of hexaploid tritordeum. Genet. Resour. Crop Evol. 64:1331-1353.

Du, P., Zhuang, L.F., Wang, Y.Z., Yuan, L., Wang, Q., Wan, D.R., Dawadondup, Tan, L.J., Shen, J., Xu, H.B., Zhao, H., Chu, C.G., Qi, Z.J. 2017. Development of oligonucleotides and multiplex probes for quick and accurate identification of wheat and Thinopyrum bessarabicum chromosomes. Genome 60:93-103.

Friebe, B., Bill, B.S. 1994. C-band polymorphism and structural rearrangements detected in common wheat (Triticum aestivum). Euphytica 78:1-5.

Fu, S.L., Chen, L., Wang, Y.Y., Li, M., Yang, Z.J., Qiu, L., Yan, B.J., Ren, Z.L., Tang, Z.X. 2015. Oligonucleotide probes for ND-FISH analysis to identify rye and wheat chromosomes. Sci. Rep. 5:10552. 
Gill, B.S., Friebe, B., Endo, T.R. 1991. Standard karyotype and nomenclature system for description of chromosome bands and structural aberrations in wheat (Triticum aestivum). Genome 34:830-839.

Han, F.P., Lamb, J.C., Birchler, A. 2006. High frequency of centromere inactivation resulting in stable dicentric chromosomes of maize. Pro. Natl. Acad. Sci. U.S.A. 103:3238-3243.

Jiang, J., Friebe, B., Gill, B.S. 1994. Chromosome painting of Amigo wheat. Theor. Appl. Genet. 89:811-813.

Kirov, I.V., Kiseleva, A.V., Laere K.V., Roy, N.V., Khrustaleva, L.I. 2017. Tandem repeats of Allium fistulosum associated with major chromosomal landmarks. Mol. Genet. Genomics 292:453-464.

Komuro, S., Endo, R., Shikata, K., Kato, A. 2013. Genomic and chromosomal distribution patterns of various repeated DNA sequences in wheat revealed by a fluorescence in situ hybridization procedure. Genome 56:131-137.

Landjeva, S., Korzun, V., Börner, A. 2007. Molecular markers: actual and potential contributions to wheat genome characterization and breeding. Euphytica 156:271-296.

Li, G.R., Gao, D., Zhang, H.G., Li, J.B., Wang, H.J., La, S.X., Ma, J.W., Yang, Z.J. 2016. Molecular cytogenetic characterization of Dasypyrum breviaristatum chromosomes in wheat background revealing the genomic divergence between Dasypyrum species. Mol. Cytogenet. 9:6.

Mirzaghaderi, G., Houben, A., Badaeva, E. 2014. Molecular-cytogenetic analysis of Aegilops triuncialis and identification of its chromosomes in the background of wheat. Mol. Cytogenet. 7:91.

Mukai, Y., Nakahara, Y., Yamamoto, M. 1993. Simultaneous discrimination of the three genomes in hexaploid wheat by multicolour fluorescence in situ hybridization using total genomic and highly repeated DNA probes. Genome 36:489-494.

Pavia, I., Carvalho, A., Rocha, L., Gaspar M.J., Lima-Brito, J. 2014. Physical location of SSR regions and cytogenetic instabilities in Pinus sylvestris chromosomes revealed by ND-FISH. J. Genet. 93:567-571.

Pedersen, C., Langridge, P. 1997. Identification of the entire chromosome complement of bread wheat by twocolour FISH. Genome 40:598-593.

Schneider, A., Linc, G., Molnár-Láng, M. 2003. Fluorescence in situ hybridization polymorphism using two repetitive DNA clones in different cultivars of wheat. Plant Breed. 122: 396-400.

Sharma, S.K., Yamamoto, M., Mukai, Y. 2016. Molecular cytogenetic approaches in exploration of important chromosomal landmarks in plants. In: Rajpal, R., Rao, S.R., Raina, S.N. (eds), Sustainable Development and Biodiversity. Springer Press. Geneva, Switzerland, pp. 127-148.

Tang, S.Y., Qiu, L., Xiao, Z.Q., Fu, S.L., Tang Z.X. 2016. New oligonucleotide probes for ND-FISH analysis to identify barley chromosomes and to investigate polymorphisms of wheat chromosomes. Genes 7:118.

Tang, Z.X., Li, M., Chen, L., Wang, Y.Y., Ren, Z.L., Fu, S.L. 2014a. New types of wheat chromosomal structural variations in derivatives of wheat-rye hybrids. PloS ONE 9:e110282.

Tang, Z.X., Yang, Z.J., Fu, S.L. 2014b. Oligonucleotides replacing the roles of repetitive sequences pAs1, pSc119.2, pTa-535, pTa71, CCS1, and pAWRC.1 for FISH analysis. J. Appl. Genetics 55:313-318.

Xiao, Z.Q., Tang, S.Y., Qiu, L., Tang, Z.X., Fu, S.L. 2017. Oligonucleotides and ND-FISH displaying different arrangements of tandem repeats and identification of Dasypyrum villosum chromosomes in wheat backgrounds. Molecules 22:973.

Zhu, M.Q., Du, P., Zhuang, L.F., Chu, C.G., Zhao, H., Qi, Z.J. 2017. A simple and efficient non-denaturing FISH method for maize chromosome differentiation using single-strand oligonucleotide probes. Genome online May 4:1-8.

\section{Electronic Supplementary Material (ESM)}

Electronic Supplementary Material (ESM) associated with this article can be found at the website of CRC at http://www.akademiai.com/content/120427/

Electronic Supplementary Table S1. The karyotype of each materials used in this study

Electronic Supplementary Figure S1. ND-FISH analysis of root tip metaphase chromosomes of 1RS.1BL translocation cultivars/lines. (a) Using probes Oligo-pSc119.2-1 (green) and Oligo-pTa-535-1 (red) analyze 04 


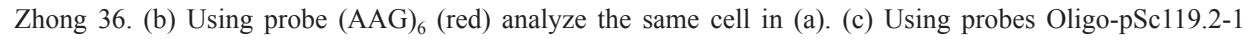
(green) and Oligo-pTa-535-1 (red) analyze Luomai 21. (d) Using probe (AAG) (red) analyze the same cell in (c). (e) Using probes Oligo-pSc119.2-1 (green) and Oligo-pTa-535-1 (red) analyze Dong 091277. (f) Using probe $(\mathrm{AAG})_{6}(\mathrm{red})$ analyze the same cell in (e). Chromosomes were counterstained with DAPI (blue). Scale bar $10 \mu \mathrm{m}$

Electronic Supplementary Figure S2. ND-FISH analysis of root tip metaphase chromosomes of 1RS.1BL translocation cultivars/lines. (a) Using probes Oligo-pSc119.2-1 (green) and Oligo-pTa-535-1 (red) analyze E'en 1. (b) Using probe (AAG) 6 (red) analyze the same cell in (a). (c) Using probes Oligo-pSc119.2-1 (green) and Oligo-pTa-535-1 (red) analyze Neixiang 188. (d) Using probe (AAG) 6 (red) analyze the same cell in (c). (e) Using probes Oligo-pSc119.2-1 (green) and Oligo-pTa-535-1 (red) analyze Chuanmai 35. (f) Using probe $(\mathrm{AAG})_{6}$ (red) analyze the same cell in (e). Chromosomes were counterstained with DAPI (blue). Scale bar $10 \mu \mathrm{m}$

Electronic Supplementary Figure S3. ND-FISH analysis of root tip metaphase chromosomes of 1RS.1BL translocation cultivars/lines. (a) Using probes Oligo-pSc119.2-1 (green) and Oligo-pTa-535-1 (red) analyze Heyou 1. (b) Using probe (AAG) 6 (red) analyze the same cell in (a). (c) Using probes Oligo-pSc119.2-1 (green) and Oligo-pTa-535-1 (red) analyze Shan 345. (d) Using probe (AAG) 6 (red) analyze the same cell in (c). (e) Using probes Oligo-pSc119.2-1 (green) and Oligo-pTa-535-1 (red) analyze Zhengmai 98. (f) Using probe $(\mathrm{AAG})_{6}$ (red) analyze the same cell in (e). Chromosomes were counterstained with DAPI (blue). Scale bar $10 \mu \mathrm{m}$

Electronic Supplementary Figure S4. ND-FISH analysis of root tip metaphase chromosomes of 1RS.1BL translocation cultivars/lines. (a) Using probes Oligo-pSc119.2-1 (green) and Oligo-pTa-535-1 (red) analyze Shi 4185. (b) Using probe (AAG) 6 (red) analyze the same cell in (a). (c) Using probes Oligo-pSc119.2-1 (green) and Oligo-pTa-535-1 (red) analyze Yannong 18. (d) Using probe (AAG) 6 (red) analyze the same cell in (c). (e) Using probes Oligo-pSc119.2-1 (green) and Oligo-pTa-535-1 (red) analyze Y7-22. (f) Using probe (AAG) (red) analyze the same cell in (e). Chromosomes were counterstained with DAPI (blue). Scale bar $10 \mu \mathrm{m}$

Electronic Supplementary Figure S5. ND-FISH analysis of root tip metaphase chromosomes of 1RS.1BL translocation cultivars/lines. (a) Using probes Oligo-pSc119.2-1 (green) and Oligo-pTa-535-1 (red) analyze Zhengyumai 033. (b) Using probe $(\mathrm{AAG})_{6}$ (red) analyze the same cell in (a). (c) Using probes OligopSc119.2-1 (green) and Oligo-pTa-535-1 (red) analyze Chuanmai 55. (d) Using probe (AAG) 6 (red) analyze the same cell in (c). (e) Using probes Oligo-pSc119.2-1 (green) and Oligo-pTa-535-1 (red) analyze Huanong

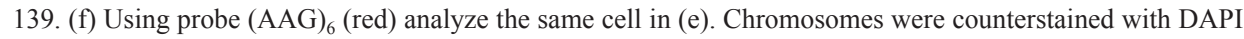
(blue). Scale bar $10 \mu \mathrm{m}$

Electronic Supplementary Figure S6. ND-FISH analysis of root tip metaphase chromosomes of 1RS.1BL translocation cultivars/lines. (a) Using probes Oligo-pSc119.2-1 (green) and Oligo-pTa-535-1 (red) analyze

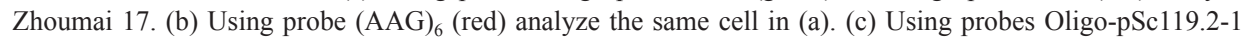
(green) and Oligo-pTa-535-1 (red) analyze Yumai 50. (d) Using probe (AAG) 6 (red) analyze the same cell in (c). Chromosomes were counterstained with DAPI (blue). Scale bar $10 \mu \mathrm{m}$

Electronic Supplementary Figure S7. ND-FISH analysis of root tip metaphase chromosomes of CS, Aurora and Amigo. (a) Using probes Oligo-pSc119.2-1 (green) and Oligo-pTa-535-1 (red) analyze CS. (b) Using probe $(\mathrm{AAG})_{6}$ (red) analyze the same cell in (a). (c) Using probes Oligo-pSc119.2-1 (green) and Oligo-pTa-535-1 (red) analyze Aurora. (d) Using probe (AAG) 6 (red) analyze the same cell in (c). (e) Using probes OligopSc119.2-1 (green) and Oligo-pTa-535-1 (red) analyze Amigo. (f) Using probe (AAG) 6 (red) analyze the same cell in (e). Chromosomes were counterstained with DAPI (blue). Scale bar $10 \mu \mathrm{m}$ 